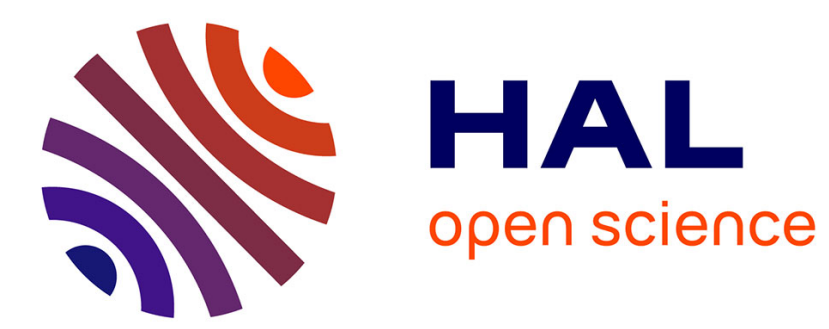

\title{
DIFFUSIVITY OF IMPURITIES ALONG MIGRATING AND STATIONARY GRAIN BOUNDARIES
}

W. Gust, M. Hintz, B. Predel

\section{- To cite this version:}

W. Gust, M. Hintz, B. Predel. DIFFUSIVITY OF IMPURITIES ALONG MIGRATING AND STATIONARY GRAIN BOUNDARIES. Journal de Physique Colloques, 1985, 46 (C4), pp.C4-529-C4-536. 10.1051/jphyscol:1985459 . jpa-00224710

\section{HAL Id: jpa-00224710 https://hal.science/jpa-00224710}

Submitted on 1 Jan 1985

HAL is a multi-disciplinary open access archive for the deposit and dissemination of scientific research documents, whether they are published or not. The documents may come from teaching and research institutions in France or abroad, or from public or private research centers.
L'archive ouverte pluridisciplinaire HAL, est destinée au dépôt et à la diffusion de documents scientifiques de niveau recherche, publiés ou non, émanant des établissements d'enseignement et de recherche français ou étrangers, des laboratoires publics ou privés. 
JOURNAL DE PHYSIQUE

Colloque $\mathrm{C} 4$, supplément au $\mathrm{n}^{\circ} 4$, Tome 46 , avril 1985

page $C 4-529$

\title{
DIFFUSIVITY OF IMPURITIES ALONG MIGRATING AND STATIONARY GRAIN BOUNDARIES
}

\author{
W. Gust, M.B. Hintz ${ }^{+}$and B. Predel \\ Max-PZanck-Institut für MetalZforschung and Institut für Metalzkunde, \\ Seestrasse 92, D-7000 Stuttgart 1, F.R.G. \\ 'Department of MetalZurgical Engineering, Michigan Technological University, \\ Houghton, MI 49931, U.S.A.
}

Résumé - Les résultats de diffusion d' impurités sont systèmatiquement comparés pour des joints en mouvement et des joints immobiles dans un grand nombre de systèmes binaires. Les résultats de diffusion relatifs aux interfaces en mouvements ont été obtenus pour différentes réactions à l' état solide (précipitation, dissolution, grossissement discontinus, deccomposition eutectöide, diffusion induite par migration de joint). Les vitesses de migration des interfaces déterminées expérimentalement varient depuis les plus rapides jusqu'aux plus lentes. Pour certains systèmes ces variations sont de six (ou plus) ordres de grandeur. Néanmoins les résultats de diffusion intergranulaire obtenus sont toujours de même ordre de grandeur que ceux obtenus dans les interfaces stationnaires pour le même alliage. On peut conclure que dans les cas présentement étudiés, la migration des joints n'induit pas une augmentation importante de la diffusion. Des exceptions à cette tendance générale peuvent cependant exister dans le système Fe-Zn.

Abstract - Diffusivity data of impurities are systematically compared for migrating and stationary grain boundaries in a number of binary systems. The diffusion data for migrating boundaries have been obtained by diffexent solid state reactions, e.g. discontinuous precipitation, discontinuous dissolution, discontinuous coarsening, eutectoid decomposition and diffusion induced grain boundary migration. The experimentally determined migration rates of the boundaries vary from very fast to extremely slow, in some individual systems varying by six or more orders of magnitude. Nevertheless, the grain boundary diffusion data obtained are always of the same order of magnitude as those for stationary boundaries in the same alloy system. It can be concluded that in these cases the migration of a grain boundary does not drastically enhance the grain boundary diffusion. Exceptions to this general behavior may, however, exist, e.g. the Fe-Zn system.

In recent studies /1-3/ it has been stated that the diffusion in migrating grain boundaries occurs about 2-4 powers of ten faster than in stationary grain boundaries. Hillert and Purdy /1/ and $\mathrm{Li}$ Chongmo and Hillert /2/ investigated the diffusion induced grain boundary migration (DIGM) in the Fe-Zn system. Smidoda, Gottschalk and Gleiter /3/ studied a combined recrystallization-precipitation process in deformed supersaturated $\mathrm{Ni}-\mathrm{Al}$ and $\mathrm{Ni}-\mathrm{Cr}-\mathrm{Al}$ solid solutions. However, for the Fe- $\mathrm{Zn}$ and Ni-Al systems no data for impurity diffusion ( $\mathrm{Fe} / \mathrm{Zn}, \mathrm{Ni} / \mathrm{Al}$ ) in stationary grain boundaries exist in the literature. Therefore, the diffusivities of the impurity atoms in migrating grain boundaries determined in the above mentioned studies /1-3/ were compared with the self-diffusion data ( $\mathrm{Fe} / \mathrm{Fe}, \underline{\mathrm{Ni}} / \mathrm{Ni}$ ) of stationary grain boundaries. This comparison is, however, not relevant because, as has already been shown for volume diffusion, the coefficient (D) for impurity diffusion can be from one to two powers of ten higher than that for self-diffusion of the matrix element (Fig. 1). In the case of grain boundary diffusion this difference can even be considerably greater because of the appearance of grain boundary segregation which, as general, leads to a drastic enrichment of the impurity atom concentration in the grain boundary. There is thus some reason to suspect that the above described reports /1-3/ of enhanced diffusivity in migrating interfaces may be due to factors other than interfacial motion. 


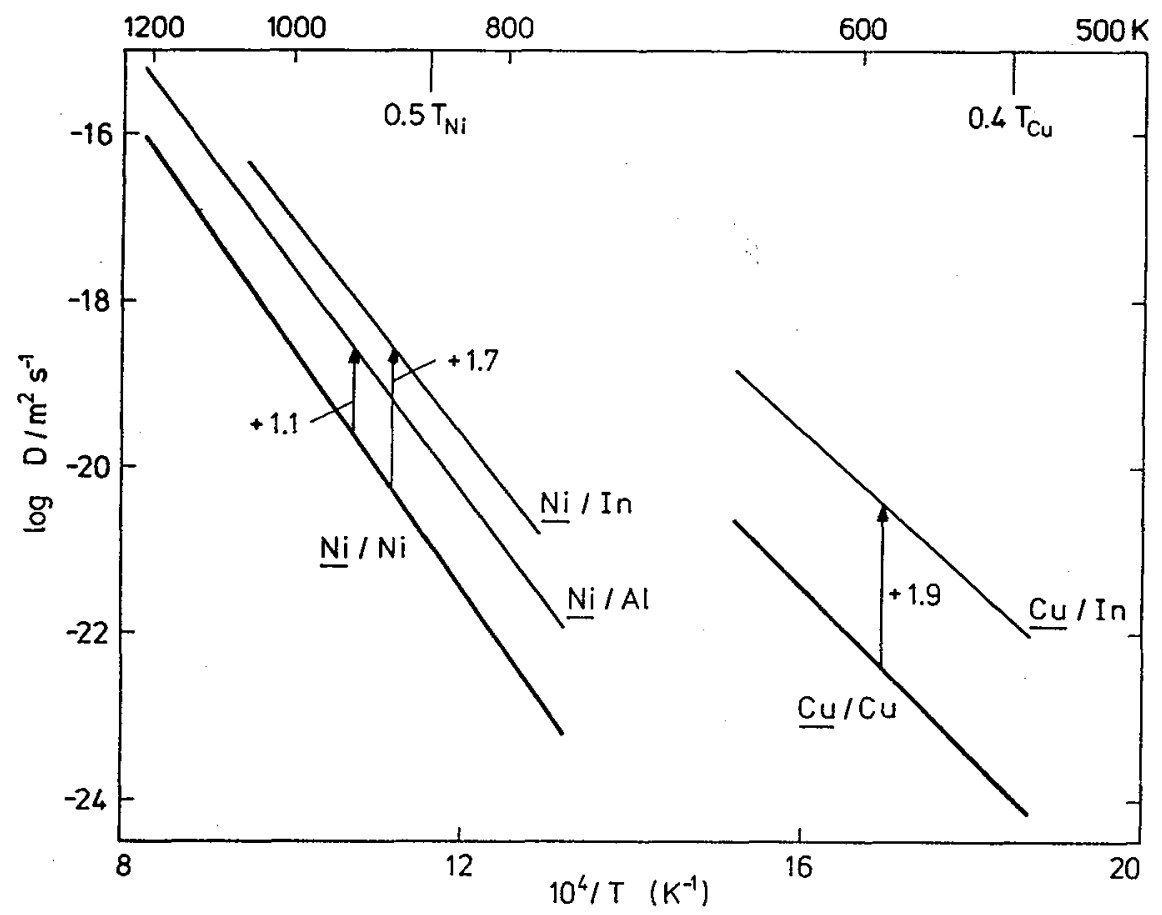

Fig. 1 - Comparison between volume impurity and volume self-diffusion in $\mathrm{Ni} / 4-6 /$ and $\mathrm{Cu} / 7,8 /$ in the temperature range relevant for migrating grain boundaries. $\mathrm{T}_{\mathrm{Ni}}, \mathrm{T}_{\mathrm{Cu}}=$ melting point of $\mathrm{Ni}$ and $\mathrm{Cu}$, respectively.

In order to examine these issues in more detail, we have systematically compared diffusion rates along migrating and stationary interfaces in all binary systems for which we could find data. There is relevant data for about 12 systems, of which 6 are presented here as examples.

1. Ni-In System - For a stationary Ni grain boundary the diffusion of In in a symmetric $39^{\circ}\langle 110\rangle$ tilt boundary was studied $/ 9 \%$. The diffusion in migrating boundaries was determined from the growth kinetics of discontinuous precipitation in $\mathrm{Ni}-7.5 \mathrm{a} / 0$ In polycrystals $/ 10 /$. In these and other works (e.g. /11/) it was shown that the growth kinetics of this solid state reaction is described best by the equations from Turnbul1/12/ and Petermann and Hornbogen /13/. According to the information in Fig. 2, the diffusivities (represented by $s \delta D_{b}$, where $s$ is a segregation factor $/ 14 /, \delta$ is the grain boundary thickness and $\mathrm{D}_{\mathrm{b}}$ is the grain boundary diffusion coefficient) for migrating and stationary boundaries are of the same order of magnitude.

2. $\mathrm{Cu}$-In System - For a stationary $\mathrm{Cu}$ grain boundary the diffusion of In in a symmetric $45^{\circ}\langle 100\rangle$ tilt boundary /15/ and in a random grain boundary /16/ was studied. For the $\mathrm{Cu}$-In system, well established data on migrating boundaries are available fxom investigations on discontinuous precipitation by various authors. In Fig. 3 the data for the random grain boundary of a $\mathrm{Cu}-4.6$ a/0 In bicrystal are reproduced /17/. Here also no significant difference between migrating and stationary grain boundaries appears to exist.

3. $\mathrm{Cu}-\mathrm{Sb}$ system - For a stationary Cu grain boundary the diffusion of sb in a symmetric $45^{\circ}\langle 100\rangle$ tilt boundary was studied /18/. For migrating boundaries data are available from investigations on the kinetics of discontinuous precipitation and dissolution in $\mathrm{Cu}-4.5 \mathrm{a} / 0 \mathrm{Sb}$ single cxystals /19/ using the equation of Petermann and Hornbogen. In 


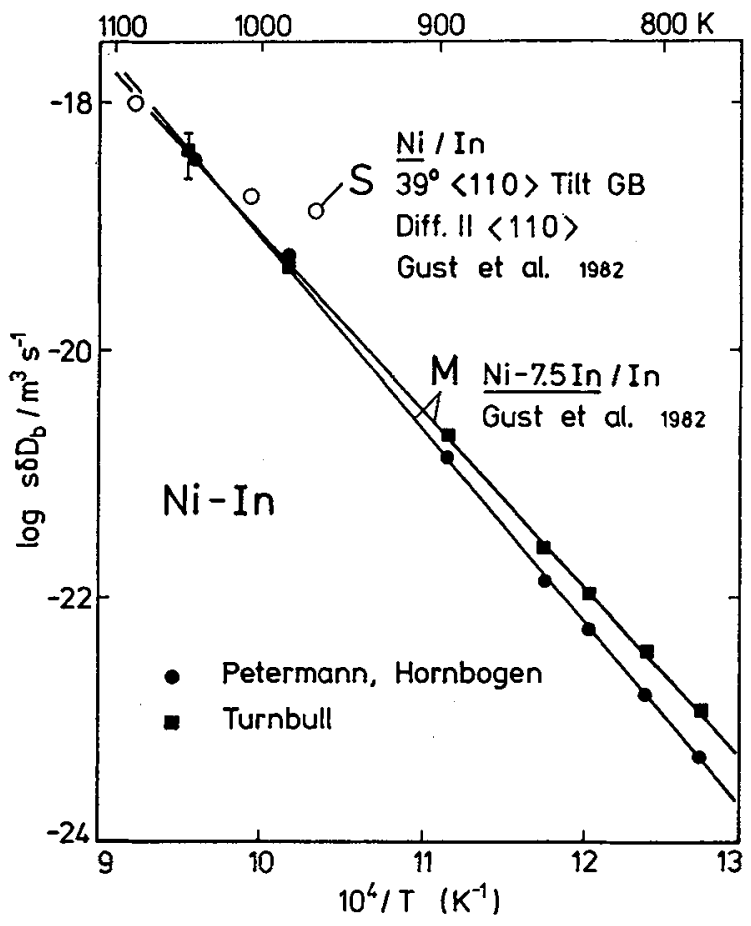

Fig. 2

Arrhenius plot of the diffusivity for stationary (S) /9/ and migrating (M) /10/ grain boundaries (GB) in the $\mathrm{Ni}-$ In system.

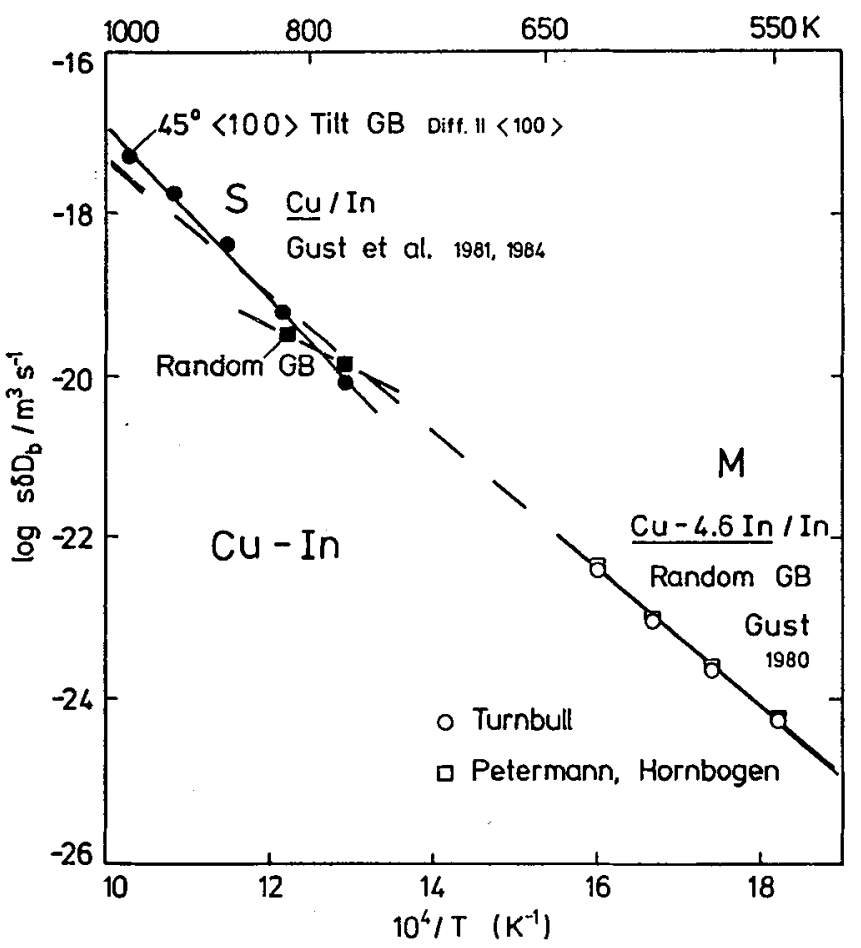

Fig. 3

Arrhenius plot of the diffusivity for stationary $/ 15,16 /$ and migrating /17/ grain boundaries in the cu-In system. 
spite of the fact that the diffusivities vary over 9 orders of madnitude, the $s \delta D_{b} v a-$ lues are roughly in agreement with each other (Fig. 4).

4. Cu-Ag System - The diffusion of Ag along stationary Cu grain boundaries was studied several times $/ 18,20-22 /$. Some of these studies were performed on symmetric $45^{\circ}\langle 100\rangle$ tilt boundaries $118,21 /$, while the others were performed on polycrystals $/ 20,22 /$. Barreau et al. /22/ used the approximate solution of Fisher and the exact solution of Suzuoka. Gertsriken et al. $/ 20 /$ also investigated the grain boundary diffusion of Ag in a Cu-0.1 a/o Ag alloy. A Cu-3.8 a/o Ag bicrystal with a xandom type boundary $/ 11 /$ and a $\mathrm{Cu}-3.0 \mathrm{a} / 0 \mathrm{Ag}$ polycrystal /18/ were used to investigate the discontinuous precipitation reaction. According to Fig. 5 the $s \delta \mathrm{D}_{\mathrm{b}}$ values for migrating boundaries are of the same order of magnitude as the literature values for stationary boundaries. These findings are supported by the results of Blackburn et al. /21/ who studied the diffusion in stationary and sliding grain boundaries. The two Arrhenius lines are obviously identical within the limits of accuracy of the measurements and offer no evidence that the diffusivity is strongly increased by grain boundary sliding $\left(1.4 \times 10^{-11}-8.4 \times 10^{-10} \mathrm{~m} / \mathrm{s}\right)$.

5. Al-Zn System - For stationary grain boundaries the diffusion of Zn in polycrystalline Al-Zn alloys was studied /24/. In Fig. 6 only the experimentally determined Arrhenius lines relevant to comparison are plotted. The diffusion data for migrating boundaries have been obtained by three different solid state reactions : discontinuous precipitation /25-28/, discontinuous coarsening /20/ and eutectoid decomposition /29/. The investigations, carried out independently of each other, show that the diffusivity of stationary as well of migrating boundaries is nearly equal.

6. Cu-Zn System - For stationary grain boundaries the diffusion of $\mathrm{Zn}$ in $\mathrm{Cu}$ and $\mathrm{Cu}-\mathrm{Zn}$ polycrystals was studied $/ 25,26 /$. Hässner $/ 30 /$ used the exact solution of Suzuoka, Klotsman et al. /31/ on the other hand used only the approximate solution of Fisher. For migrating grain boundaries $\mathrm{Li}$ Chongmo and Hillert /32/ determined the diffusivity by a study of DIGM. In this study/32/it is stated that the diffusion in migrating grain boundaries is almost 2 orders of magnitude faster than that in stationary boundaries. According to Fig. 7 we cannot join in this conclusion.

Discussion - According to the information in Figs. 2-7 the diffusivities in migrating and stationary boundaries are of the same order of magnitude for all systems. It is noteworthy that the migration rates of the individual reactions vary very markedly (Fig. 8). They range from very slow $\left(10^{-12} \mathrm{~m} / \mathrm{s}\right)$ to extremely fast $\left(10^{-5} \mathrm{~m} / \mathrm{s}\right)$. No great increase in diffusion rate is observed to accompany even the extremely fast migration rates. In compaxison to these migration rates the rates observed for DIGM are more than 4 powers of ten slower. If a significantly increased diffusivity would be generally observable for DIGM, this would also be expected for the other solid state reactions (DP, DD, DC, ED). The experimental findings of almost all systems show, however, that this is not the case.

A simple theoretical consideration also suggests that increases in diffusivity due to interfacial motion are probably not to be expected. The maximum migration rate amounts to somewhat more than $3 \times 10^{-6} \mathrm{~m} / \mathrm{s}$ (cf. Fig. 8). With an assumed diffusion jump length of $3 \times 10^{-10} \mathrm{~m}(3 \AA)$, a time interval of $10^{-4} \mathrm{~s}$ is yielded for an atomic diffusion jump in the migration direction. However, because the atomic vibration frequency amounts to about $10^{13} \mathrm{~s}^{-1}$ (Debye frequency), about $10^{9}$ vibrations occur in this time interval. That means that every atom makes on average $10^{9}$ vibrations before a diffusional jump takes place. As a consequence, for the diffusing atoms themselves, the fastest migrating boundaries can be viewed as quasi stationary grain boundaries whose diffusion behavior should be similar to that of stationary boundaries.

Binary alloy systems, for which relevant comparison data exist in the literature for migrating and stationary boundaries, behave according to these theoretical considerations. To our knowledge there is no exception to this. Ongoing studies/33/ of diffusion of $59 \mathrm{Fe}$ and $65 \mathrm{Zn}$ in stationary grain boundaries of $\alpha$-Fe have nevertheless lead to a surprising result. According to this study the diffusivities of $\mathrm{Fe}$ and $\mathrm{Zn}$ are of the same order of magnitude. This would mean that in the Fe-zn system the diffusivities obtained from DIGM /1,2/ actually lie about 4 orders of magnitude higher than the values for 

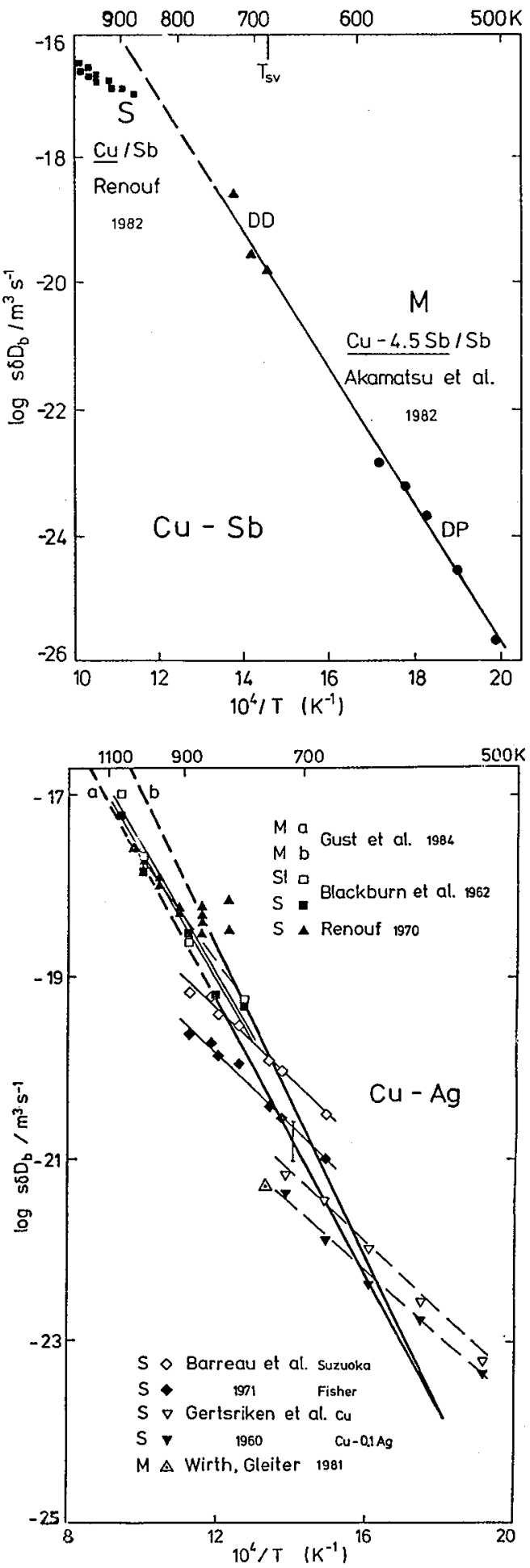

Fig. 4

Arrhenius plot of the diffusivity for stationary /18/ and migrating /19/ grain boundaries in the $\mathrm{Cu}-\mathrm{Sb}$ system. DP discontinous precipitation, DD discontinous dissolution.
Fig. 5

Arrhenius plot of the diffusivity for stationary $/ 18,20-22 /$, migrating /11/ and sliding ( $S$ ) /21/ grain boundaries in the Cu-Ag system. a Turnbull, b Petermann and Hornbogen. 


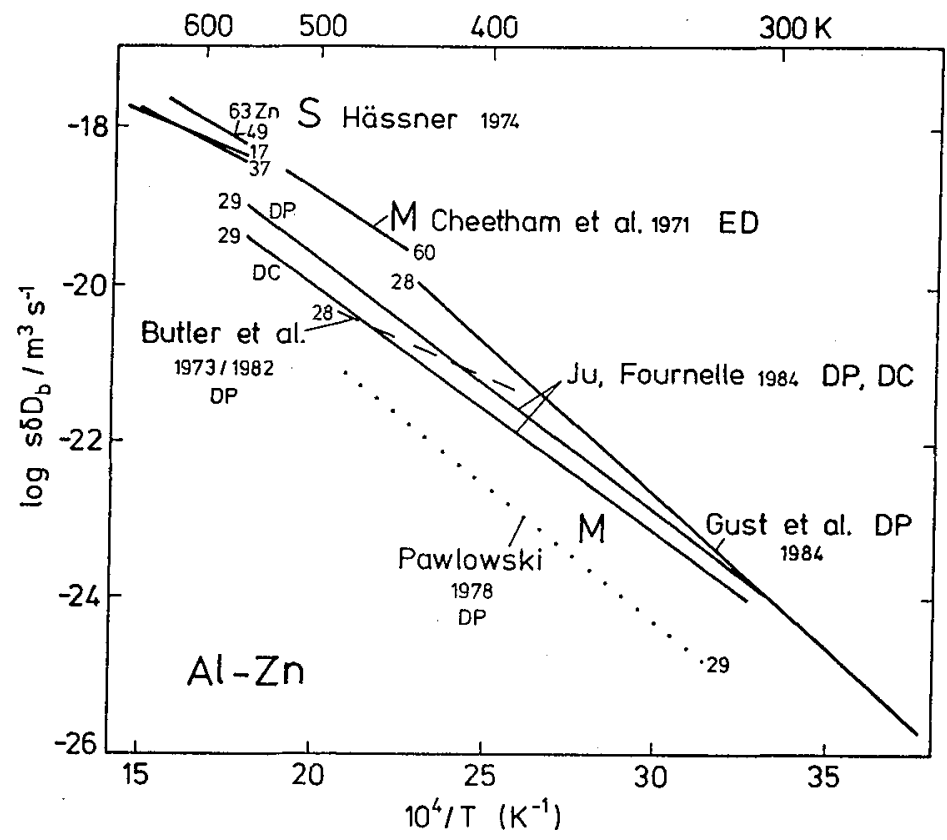

Fig. 6

Arrhenius plot of the diffusivity for stationary /24/ and migrating /25-28/ grain boundaries in the Al-Zn system. The numbers of the respective Arrhenius lines are representing the $\mathrm{Zn}$ content $(a / 0)$. DP discontinous precipitation, DC discontinous coarsening, ED eutectoid decomposition.

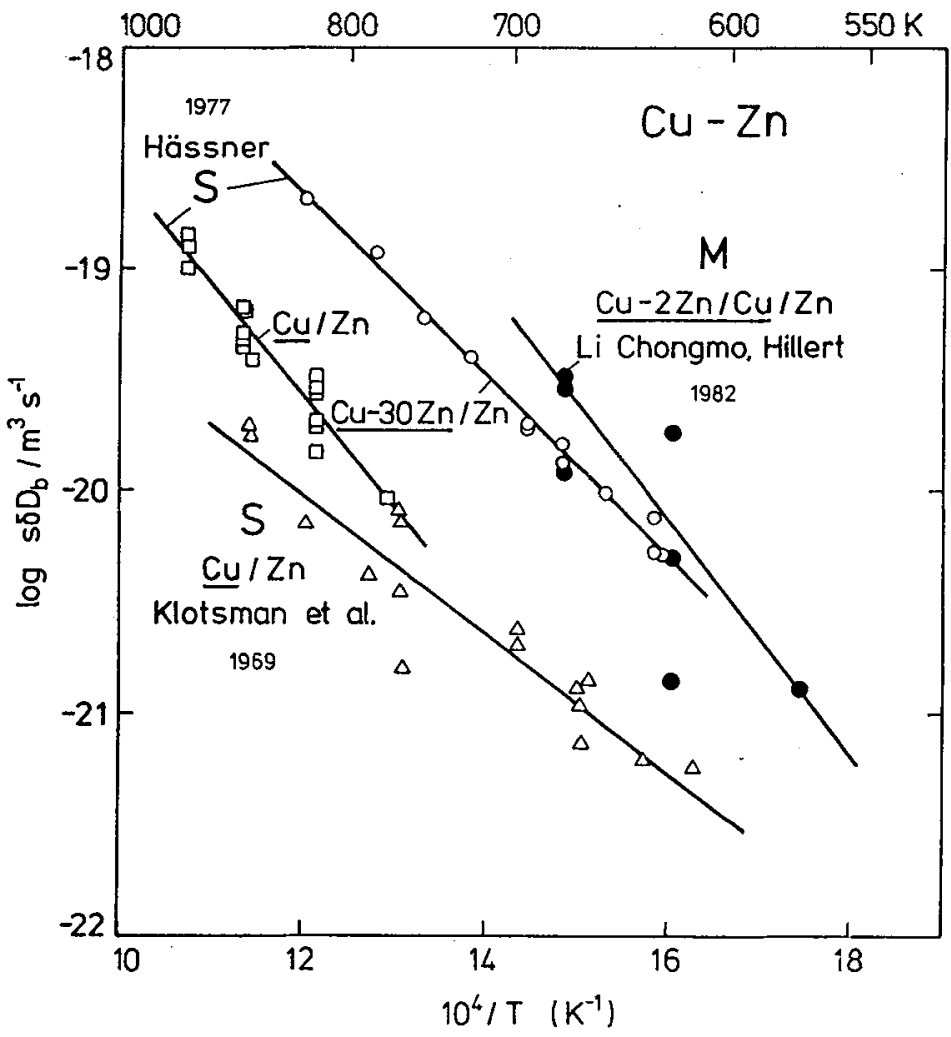

Fig. 7

Arrhenius plot of the diffusivity for stationary /30,31/ and migrating /32/ grain boundaries in the Cu-Zn system. 


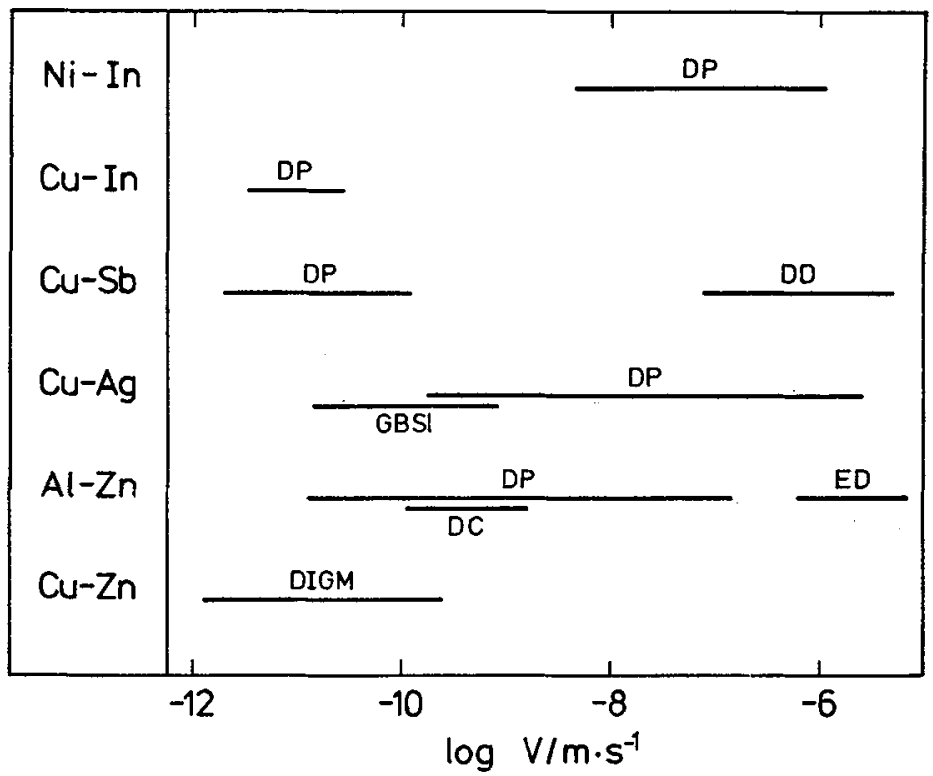

Fig. 8 - Rates (V) for migration and sliding in different systems caused by discontinuous precipitation (DP), discontinuous coarsening (DC), discontinuous dissolution (DD), eutectoid decomposition (ED), diffusion induced grain boundary migration (DIGM) and grain boundary sliding (GBSl).

stationary boundaries. This information should, however, be considered with a certain degree of caution because various groups working on the volume diffusion of $\mathrm{zn}$ in $\alpha$-Fe have obtained very different results which have been attributed to the influence of unwanted impurities. If this explanation holds true, this influence could be even stronger in the case of grain boundary diffusion. Therefore, the data for diffusion of $\mathrm{Zn}$ in stationary grain boundaries of $\alpha-F e$ must still be further confirmed.

Independent of whether the preliminary findings for $\alpha-\mathrm{Fe} / \mathrm{Zn}$ diffusion in stationary boundaries are confirmed or whether they are not, the total of the experimental facts can be summarized as follows: Grain boundary migration does not as a rule lead to a dxastic increase in the grain boundary diffusion. There may, however, be exeptions, for example, the Fe- $\mathrm{zn}$ system. This conclusion is supported in a recent review article by Balluffi where addition data and discussion are given $/ 34 /$.

\section{References}

1. M. Hillert and G.R. Purdy, Acta Metall. $\frac{26}{29}$ (1978) 333.

2. Li Chongmo and M. Hillert, Acta Metall. $\overline{29}$ (1981) 1949.

3. K. Smidoda, C. Gottschalk and H. Gleiter, Acta Metall. 26 (1978) 1833; Met. Sci. 13 (1979) 146 .

4. K. Maier, H. Mehrer, E. Lessmann and W. Schüle, phys. stat. sol. (b) 78 (1976) 689.

5. W. Gust, M.B. Hintz, A. Lodding, H. Odelius and B. Predel, phys. stat. sol. (a) 64 (1981) 187 .

6. W. Gust, M.B. Hintz, A. Lodding and H. Odelius, Phil. Mag. A43 (1981) 1205.

7. K. Maier, phys. stat. sol. (a) 44 (1977) 576.

8. W. Gust, A. Lodding, H. Odelius, C. Ostertag, B. Predel and U. Roll, Phil. Mag. A47 (1983) 395 .

9. W. Gust, M.B. Hintz, A. Lodding, H. Odelius and B. Predel, Acta Metal1. 30 (1982) 75. 
10. W. Gust, U. Leininger and B. Predel, in Proc. Int. Conf. Solid-Solid Phase Transformations, H.I. Aaronson et al. (eds.), The Metall. Soc. AIME, New York (1982) 927.

11. W. Gust, G. Beuers, J. Steffen, S. Stilz and B. Predel, Acta Metall. 33 (1985), to be published.

12. D. Turnbull, Acta Metall. 3 (1955) 55.

13. J. Petermann and E. Hornbogen, Z. Metallk. 59 (1968) 814.

14. G.B. Gi.bbs, phys. stat. sol. 16 (1966) K 27.

15. W. Gust, A. Lodding, H. Odelius, B. Predel and U. Roll, in DIMETA-82, Diffusion in Metals and Alloys, F.J. Kedves et al. (eds.), Trans Tech Publications, Aedermannsdorf (1983) 418 .

16. W. Gust, M.B. Hintz, A. Lodding, H. Odelius and U. Roll, Mikrochimica Acta, Suppl. 9 (1981) 307 .

17. W. Gust, Habilitation Thesis, Stuttgart (1980) 124.

18. T.J. Renouf, Phil. Mag. 22 (1970) 359.

19. K. Akamatsu, $W$. Gust, M.B. Hintz and B. Predel, in Proc. Int. Conf. Solid-Solid Phase Transformations, H.I. Aaronson et al. (eds.), The Metall. Soc. AIME, New York (1982) 933.

20. S.D. Gertsriken and A.L. Revo, Fiz. Met. Metalloved. 9 (1960) 578; Phys. Met. Metallogr. 9 (4) (1960) 92 .

21. D.A. Blackburn and A.F. Brown, J. Inst. Met. 91 (1962-63) 106; in Radioisotopes in the Physical Sciences and Industry, I, Proc. Conf., Copenhagen, September 6-17, 1960, ed. by Int. Atomic Energy Agency, Vienna (1962) 145.

22. G. Barreau, G. Brunel, G. Cizeron and P. Lacombe, Mém. Sci. Rev. Métall. 68 (1971) 357; C.R. Acad. Sci. (Paris) 270 (1970) 516.

23. R. Wirth and H. Gleiter, Acta Metall. 29 (1981) 1825.

24. A. Hässner, Kristall und Technik 9 (1974) 1371.

25. C.P. Ju and R.A. Fournelle, Acta Metall., in press.

26. W. Gust, M.B. Hintz, R. Lučić and B. Predel, in Phase Transformations in solids, T. Tsakalakos (ed.), North-Holland, New York (1984) 513.

27. A. Pawlowski, Scientific Bulletins of the Stanislaw Staszic Uni. Min. Metall., No. 676, Metallurgy and Foundry Practice, Bulletin 81, Akademia Gorniczo-Hutnicza Im. S. Staszica W Krakowie, Cracow (1978) 1-108; Arch. Hutn. 22 (1977) 621.

28. E.P. Butler, V. Ramaswamy and P.R. Swann, Acta Metall. 21 (1973) 517, see also: R.A. Fournelle and C.P. Ju, in Proc. Int. Conf. Solid-solid phase Transfermations, H.I. Aaronson et al. (eds.), The Metall. Soc. AIME, New York (1982) 959.

29. D. Cheetham and N. Ridley, J. Inst. Metals 99 (1971) 371.

30. A. Hässner, Wiss. Z. d. Techn. Hochsch. Kar1-Marx-Stadt 19 (1977) 619.

31. S.M. Klotsman, Ya. A. Rabovskiy, V.K. Talinskiy and A.N. Timofeyev, Phys. Met. Metallogr. 28 (6) (1969) 66.

32. Li Chongmo and $M$. Hillert, Acta Metall. 30 (1982) 1133.

33. J. Geise, P. Neuhaus, C. Herzig, W. Gust and B. Predel, Scripta Metall., to be published.

34. R.w. Balluffi, Met. Trans. A 13 (1982) 2069. 